\title{
The Effectiveness of a Brief Intervention for Reducing Adolescent Alcohol Consumption
}

\author{
Efectividad de una intervención breve \\ para reducir el consumo de alcohol \\ en adolescentes
}

\section{Efetividade de uma Intervenção breve para reduzir o consumo de álcool em adolescentes}

\author{
Karina Conde, $\mathrm{PhD}^{1 *}$; \\ Romina Antonela Brandariz, BSc'; \\ Aldana Lichtenberger, BSc룰 \\ Mariana Cremonte, $\mathrm{PhD}^{1}$
}

Received: February 9th, 2017 / Accepted: March 14th, 2018

Dor: http://dx.doi.org/10.12804/revistas.urosario.edu.co/revsalud/a.7261

To cite this article: Conde K, Brandariz RA, Lichtenberger A, Cremonte M. The Effectiveness of a Brief Intervention for Reducing Adolescent Alcohol Consumption. Rev Cienc Salud. 2018;16(3):393-407. Dor: http://dx.doi.org/10.12804/revistas.urosario.edu.co/revsalud/a.7261

\section{Abstract}

Introduction: Although alcohol consumption affects more than half of all adolescents, there are no known studies to assess the effectiveness of interventions to prevent or reduce consumption at a local level. The aim of this randomized clinical trial was to determine the effectiveness and clinical significance of a brief intervention program to reduce the consumption of alcohol and related problems in an educational setting in Argentina. Materials and methods: Systematically selected high school students $(\mathrm{N}=167)$ were randomly assigned to one of three conditions: two control groups (screening, screening and evaluation) and one experimental group (screening, assessment and intervention). With the approval of an Ethics Committee, we implemented a protocol based on international guidelines. The effectiveness measures used were reduction in usual quantity, in high-risk alcohol drinking or in alcohol-related problems. We performed descriptive analyses, linear and logistic regressions, estimates of relative and absolute risk reduction, and the number of patients needed to reduce an event. In the follow-up ( $\mathrm{N}=150$ ), the quantity of consumption and high-risk consumption were higher in the control

1 Instituto de Psicología Básica, Aplicada y Tecnología, Universidad Nacional de Mar del Plata, Consejo Nacional de Investigaciones Científicas y Técnicas.

Corresponding author: kconde@mdp.edu.ar 
groups. Results: The intervention effectively reduced alcohol consumption and related problems in about one out of seven adolescents, with a minimal investment in training and implementation. However, we did not find significant differences in alcohol-related problems among the groups, which decreased under all conditions. Conclusion: Long-term studies could determine whether this change primarily affects the intervention group.

Keywords: Alcohol consumption, brief intervention, adolescent, Argentina.

\section{Resumen}

Introducción: A pesar de que el consumo de alcohol afecta a más de la mitad de los adolescentes, se desconoce la efectividad de intervenciones para evitarlo o reducirlo a nivel local. Este ensayo clínico aleatorizado se propuso determinar la efectividad y significancia clínica de un programa de intervención breve para reducir el consumo de bebidas alcohólicas y problemas relacionados en un contexto educativo de Argentina. Materiales y métodos: Los participantes, estudiantes de educación media seleccionados sistemáticamente $(\mathrm{N}=167)$ fueron asignados aleatoriamente a una de tres condiciones: dos grupos control (tamizaje, tamizaje y evaluación) y uno experimental (tamizaje, evaluación e intervención). Con el aval de un Comité de Ética, se implementó un protocolo basado en lineamientos internacionales. Las medidas de efectividad utilizadas fueron disminución de la cantidad habitual, del consumo de alto riesgo, y de los problemas relacionados con el alcohol. Se realizaron análisis descriptivos, regresiones lineales y logísticas, y estimaciones de reducción relativa y absoluta del riesgo y del número de pacientes a tratar para reducir un evento. En la etapa de seguimiento $(\mathrm{N}=150)$, la cantidad y el consumo de alcohol de alto riesgo fueron mayores en los grupos control. Resultados: la intervención redujo efectivamente el consumo de alcohol y sus problemas en aproximadamente uno de cada siete adolescentes, con una mínima inversión en entrenamiento y aplicación. Sin embargo, no se encontraron diferencias significativas en los problemas relacionados, que disminuyeron en todas las condiciones. Conclusión: Estudios a largo plazo podrían dilucidar si el cambio se sostiene mayormente en el grupo de intervención.

Palabras clave: consumo de bebidas alcohólicas, intervención breve, adolescentes, Argentina.

\section{Resumo}

Introdução: A pesar de que o consumo de álcool afeta a mais da metade dos adolescentes, desconhece-se a efetividade de intervenções para evitá-lo ou reduzi-lo no nível local. Este ensaio clínico aleatorizado se propôs determinar a efetividade e significância clínica de um programa de intervenção breve para reduzir o consumo de bebidas alcoólicas e problemas relacionados em um contexto educativo da Argentina. Materiais e métodos: Os participantes, estudantes de educação média selecionados sistematicamente $(\mathrm{N}=167)$ foram assignados aleatoriamente a três condições: dois grupos controle (peneiração, peneiração e avaliação) e um experimental (peneiração, avaliação e intervenção). Com o aval de um Comitê de Ética, se implementou um protocolo baseado em diretrizes internacionais. As medidas de efetividade utilizadas foram diminuição da quantidade habitual, do consumo de alto risco, e dos problemas relacionados com o álcool. Realizaram-se análises descritivas, regressões lineais e logísticas e estimações de redução relativa e absoluta do risco e do número de pacientes a tratar para reduzir um evento. $\mathrm{Na}$ etapa de seguimento $(\mathrm{N}=150)$, a quantidade e o consumo de álcool de alto risco foram maiores nos grupos controle. Resultados: A intervenção reduziu efetivamente o consumo de álcool e seus problemas em aproximadamente um de cada sete adolescentes, com um mínimo investimento em treinamento e aplicação. No entanto, não se encontraram diferenças significativas nos problemas relacionados, que diminuíram em todas as condições. Conclusão: Estudos a longo prazo poderiam dilucidar se a mudança se sustenta maiormente no grupo de intervenção.

Palavras-chave: consumo de bebidas alcoólicas, intervenção breve, adolescentes, Argentina. 


\section{Introduction}

$\mathrm{I}^{\mathrm{n}}$ n the year 2010, the World Health Organization (wHo) developed a global strategy to reduce the harmful consumption of alcohol. Due to the alarmingly detrimental effects of alcohol on people's lives, the who strategy focused particularly on at-risk populations such as youth, and proposed mobilizing resources for damage reduction (1). Nevertheless, an ever-increasing numbers of adolescents consume alcohol around the world, particularly in countries with limited resources such as Argentina, where practically every adolescent has consumed alcohol at least once, and $50 \%$ have done so in the most recent month $(2,3)$. Although any consumption of alcohol by developing persons is a cause of concern from a public health point of view and regulations prohibit the sale of alcoholic beverages to minors, the consumption of five or more alcoholic drinks by males or four or more alcoholic drinks by females on a single occasion has become a typical consumption pattern for young people, including $63 \%$ of Argentine teenagers $(1,3,4)$. This heavy consumption leading to intoxication exposes young people to many harmful consequences for their physical, mental, and social well-being; an unfortunate circumstance that is the motivation for prioritizing the development and identification of effective programs for preventing or delaying the initiation of alcohol consumption by young people and intervening on behalf of those young people already with a problematic consumption of alcohol (5-7).

In response to the above, a growing number of studies have been directed toward evaluating the tool for which the greatest amount of supporting evidence has been presented up to this time: the brief intervention (BI). The objective of the вг is to identify a current or potential problem concerning alcohol (harmful or risky consumption) and motivate the person to abstain from alcohol or to adopt a less risky pattern of consumption. This is accomplished by means of an interview that includes an overall evaluation of the person's consumption and a short counseling session, the main characteristic of which is its brevity, since it takes place in a single session lasting 15 minutes or less. BI procedures can be conducted by professionals from different disciplines including nurses, physicians, psychologists, nutritionists, or social workers, or by non-specialists after a brief training session (8). There are a variety of structured models for evaluation and assessment with their own recommended evaluation instruments, intervention guides, and materials for participants. Almost all of them include a series of active elements that follow the principles of the motivational interview, including feedback on evaluation results, strategies for reducing consumption or achieving abstinence, the establishment of healthy goals, empathy on the part of the person conducting the bi, and the promotion of self-efficacy, among others (9). These elements are supported by different theoretical orientations and provide for a set of common practices (10). The most relevant models for вI are those that have been developed by the World Health Organization, the National Institute of Alcohol Abuse and Alcoholism (NIAAA), and in the context of Screening, Brief Intervention, and Referral 
to Treatment (SBIRT), but only isolated elements of these approaches have been independently examined; their overall effectiveness has not been independently compared (11-14).

The mechanisms that make а вг effective are still being evaluated. They do include, however, a motivation for change, cognitive dissonance, self-efficacy, the norms of young adults regarding alcohol consumption, the intention to use protective behavioral strategies, and the use of such strategies (15). Many years of research and more than 150 controlled studies have demonstrated that BIs can be as effective as more comprehensive treatments, especially in emergency room and primary care settings, and with young students in schools and universities $(7,8)$. Brief interventions are also very well accepted by the personnel who carry them out and by participants $(16,17)$.

While some aspects of alcohol consumption by youth, and patterns of use such as consumption to excess, are shared in large parts of the world, other contextual differences should be recognized. For example, consumption is greater in our context than in other parts of the world. Likewise, consumption by adolescents is culturally accepted in our social context, and the consequences of harmful use are often more severe (18). Although abstinence should be promoted among youth and the development of policies to delay their initiation of consumption is imperative, BI should be considered for adolescents as a fundamental tool for secondary prevention. As far as we know no studies to evaluate the effectiveness of вг among adolescents have been conducted in our region. Thus, the goal of this study was to determine the effectiveness of а вг program for adolescents in reducing alcohol consumption and related problems in a school setting in the city of Mar del Plata, Argentina. The clinical significance of the program was also evaluated through estimates according to the level of risk of alcohol consumption and related problems. Since it has been observed that alcohol consumption is also usually reduced in the control group, though to a lesser extent than in the experimental group, it was decided to follow the suggestion of some researchers to use two control groups: one in which the consumption of alcohol and associated problems would be evaluated just as they were evaluated in the experimental group, and another with only a minimal evaluation of consumption, a procedure called screening (19). This procedure seeks to quickly indicate the probability of suffering from alcohol-related problems (10).

\section{Materials and methods}

This randomized clinical trial had a factorial experimental design with the assignment of three possible conditions: screening (G1, the minimally-evaluated control group), screening and evaluation (G2, the control group), and screening, evaluation, and intervention (G3, the experimental group). 


\section{Participants}

The criterion for selecting participants was that they be secondary school students attending a publicly managed technical school in the city of Mar del Plata, Argentina. The sample was selected systematically, at the beginning of the trial (Phase 1, April-July 2011), consisting of 167 students. There were 150 participants in the follow-up stage (Phase 2, August-November 2011), a $10 \%$ drop off in the size of the sample primarily due to non-attendance at school. Figure 1 details the flow of participants at each phase and provides data on the makeup of the sample.

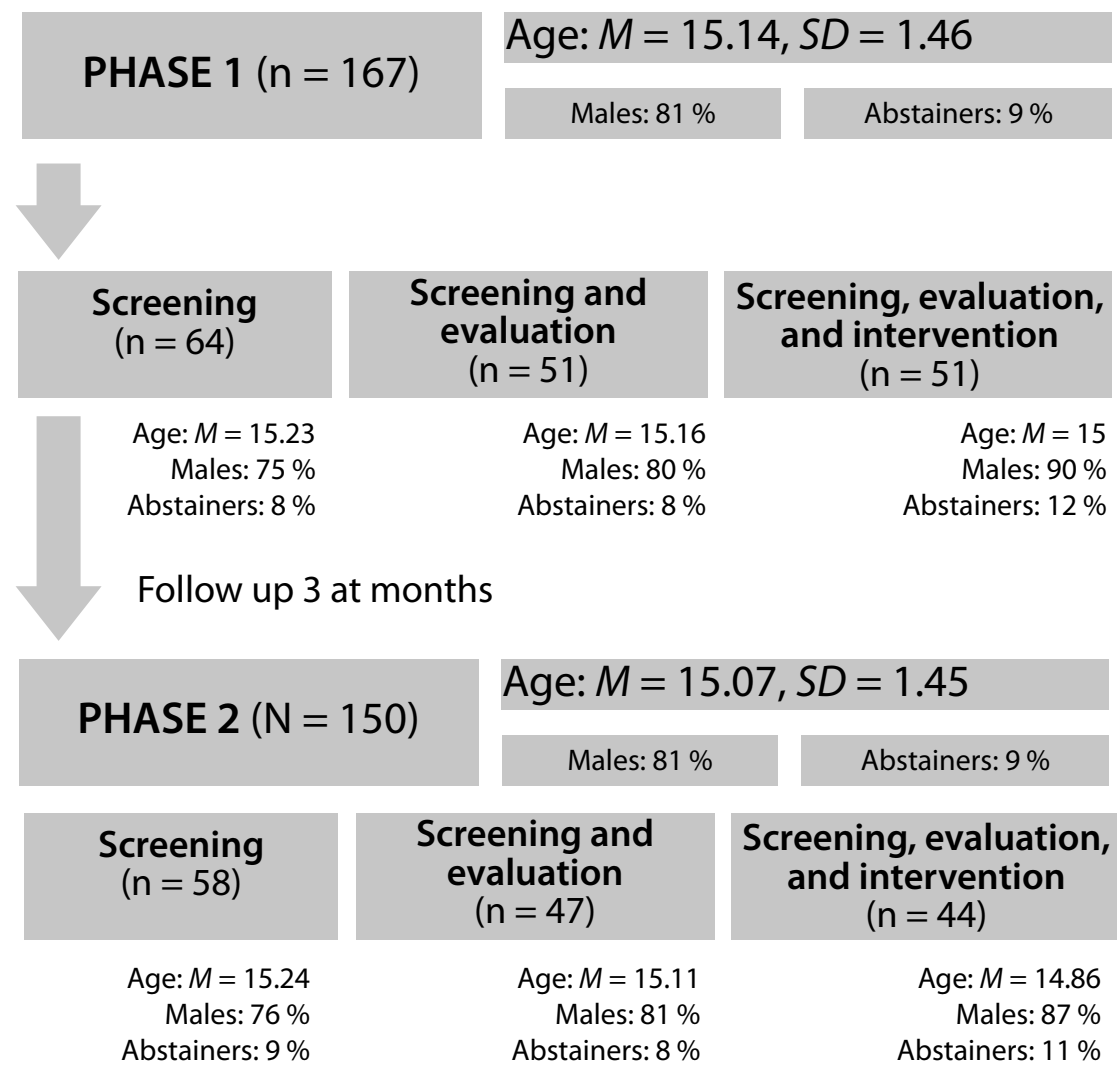

Figure 1. Flow of participants in each phase of the experiment among secondary school students, Mar del Plata, 2011

\section{Instruments}

An ad hoc intervention protocol was designed, entailing the adaptation of other referents (11-13). It included the following steps:

1. Standardized screening. All participants (G1, G2, and G3) were evaluated for alcohol consumption and related problems using the Alcohol Use Disorders Identification Test (AUDIT) (20).

2. The evaluation of alcohol-related problems and the motivation for change. Groups $\mathrm{G} 2$ and G3 were evaluated for the type and degree of problems associated with alcohol 
consumption, using an abbreviated inventory of relevant characteristics derived from the Rutgers Alcohol Problem Index (RAPI) designed by White and Labouvie (1989) (21, 22). Motivation for change was estimated using a scale, the Readiness Ruler, which measures the individual's disposition to change as determined by the motivational interview (9).

3. Brief Intervention. The complete intervention protocol was carried out exclusively in G3. Graphic materials were used to guide the intervention and were then given to each student. The following steps were included: 1. Feedback: after the AudrT was administered, students received personalized feedback regarding their level of consumption and its meaning with respect to potential adverse consequences. 2. Exploring associated problems: when high-risk consumption was detected, questions were asked regarding the problems that were experienced. If, on the other hand, consumption was characterized as lower level of risk (any consumption is considered risky for adolescents) or not risky (no consumption), abstinence was encouraged. Abstinence was positively reinforced and those students who reported not consuming alcohol were congratulated. In either case, students were advised of the adverse consequences of initiating or maintaining consumption. 3. Motivating abstinence: positive reasons for achieving or maintaining abstinence were explored. 4. Goal-setting: in the case of participants that consumed alcohol, abstinence was first suggested and encouraged, in the case of a negative response, reducing frequency and volume of consumption were proposed. Abstainers were encouraged to continue this behavior. 5. Psycho-education and positive feedback: Finally, standard units of alcoholic beverages were explained to members of G3, and recommendations were developed for reducing or ending consumption. The intervention ended with positive feedback on participants' commitments.

Regarding the performed measurements for both Phase 1 and Phase 2, the usual quantity consumed on a single occasion was estimated in standard units of alcohol (UA), each of which describes any drink containing approximately $11 \mathrm{~g}$ of pure alcohol (a quantitative variable). The period of time taken into consideration in both cases was the three months prior to measurement. This variable was re-codified into two categories: (1) habitual high-risk consumption (dichotomous variable: yes/no), for persons whose habitual quantity of consumption was greater than 3, and (2) reduced quantity of habitual consumption or continued abstinence (dichotomous variable: effective/ineffective). All those in Phase 2 who had reduced their habitual quantity of consumption with respect to Phase 1 or who had maintained abstinence were categorized as effective.

Those categorized as positive for high-risky consumption included 12-15 year-old students who had ingested three or more standard units on any occasion and 16-20 year-old students who had consumed five or more units on any occasion during the previous 12 months (Phase 1) or during the previous three months (Phase 2). The two resulting variables were later used to estimate the 
reduction of high-risk consumption or the maintenance of lower risk or non-risky consumption (dichotomous variable: effective/ineffective). All those who presented with high-risk consumption in Phase 1 and did not so present in Phase 2, as well as those who did not present with high-risk consumption at first, and maintained it, were categorized as effective.

Alcohol-related problems were evaluated using AuDIT, a 10-item questionnaire that estimates consumption and the frequency of related problems on a scale of 0-40 (a quantitative variable), validated for the local context, assessing the three months previous to each estimate. This variable was recodified as positive/negative with a cutoff of six points, as recommended for adolescents $(23,24)$. The reduction of alcohol related problems was also evaluated. Those who were positive in Phase 1 and negative in Phase 2 were categorized as effective, as were those who were negative in both phases (dichotomous variable: effective/ineffective).

Each student was assigned a unique code for subsequent follow-up. To assure the equivalency of the control and experimental groups, the students were divided into two groups based on the presence or absence of high-risk consumption. Members of the two groups were assigned to each of the conditions (G1, G2, G3) through random selection by the principal investigator, using their unique codes.

\section{Procedure}

The first step of the procedure was for representatives of the school to contact students and obtain their consent. Then, the informed consent of parents or guardians was requested through written communication. Once informed consent was obtained, students were asked to assent to their participation in the study. In each case, the general topic of the study was communicated along with the voluntary, anonymous, and confidential nature of participation. Recruitment was carried out in classrooms, while data collection and interventions were carried out in a space provided by the school. Interventions were applied individually to participants by study personnel with knowledge in the area of psychology who had attended training sessions regarding the application of the protocol. The study was approved by the Ethics Committee of the National Institute of Epidemiology.

\section{Data Analysis}

The quantity of alcohol consumed, the prevalence of risky consumption, and alcohol-related problems were subjected to descriptive analyses in Phase 1 and Phase 2. A linear regression analysis (using all independent variables) with the quantitative variables was conducted to determine changes to the variables under each given condition in Phase 1 and Phase 2, exploring the fulfillment of conditions by observing the linearity of results and normality in outlier distribution. In two separate models, the quantity of alcohol consumed, and alcohol-related problems were predicted for Phase 2 in each group (G1, G2, G3; reference category: G3), including, 
as control variables, the quantity of alcohol consumed and related problems, respectively, in Phase 1. In both cases, the possible effects of interaction between the two predictive variables were evaluated. High risk consumption in Phase 2 was also predicted using logistic regressions (reference category: no) with the group to which students belonged (reference category: G3), adding high-risk consumption in Phase 1 as a control variable (reference category: no). Measures were also included for evaluating clinical significance using the following variables: reduction of quantity of alcohol consumed or maintenance of abstinence; reduction of high-risk consumption or maintenance of a risky or non-risky level of consumption; the reduction of related problems or lack of related problems in both phases, paying special attention to changes among the high-risk group, and those positive for alcohol-related problems according to Audrr in Phase 1.

Estimates were made of Risk Reduction (RR), Relative Risk Reduction (RRR), Absolute Risk Reduction (ARR), and the number needed to treat to reduce an event (NNT). These analyses were conducted using the software R 3.3.1.

\section{Results}

T

able 1 presents the average quantity of alcohol consumed, the percentage of high-risk consumption, and the average number of alcohol related problems in Phase 1 and Phase 2 for each group. Segmented analyses according to high-risk groups are also represented in Figure 2.

Regression analyses indicated a greater quantity of alcohol consumed in the control groups during Phase 2, even when controlling for consumption in Phase 1 (table 2). Analyses of interaction between consumption in Phase 1 and the kind of group indicated that the effect of quantity (i.e. greater consumption in Phase 1, greater consumption in Phase 2) was significantly reduced in G3 compared to G1 ( $\beta=-.79$ [CI $95 \%-.9 /-22$ ], $p=.0001$ ) and G2 ( $\beta=$ -.56 [CI $95 \%-1.09 /-.48, p=.0012$ ). Significant differences in high-risk consumption between the conditions were also found, controlling for high-risk consumption in Phase 1. High-risk consumption was lesser in G3 compared to G1 (OR =.24 [CI $95 \% .08-.74$ ], $\mathrm{p}=.0126$ ) and to G2 $(\mathrm{OR}=.23$ [CI $95 \% .07-.75], \mathrm{p}=.0143)$. This model explained $46 \%$ of the variance (Nagelkerke's $\mathrm{R} 2=.4597)$ and the Hosmer-Lemeshow test $(\mathrm{X} 2=1.5806, \mathrm{gl}=4, \mathrm{p}=.8122)$ indicated a good match (not shown in the tables). No significant differences were found in consumption-related problems between the conditions (table 2), nor were significant differences found in the interaction between related problems in Phase 1 and the different conditions.

Table 3 presents results of the analyses of clinical significance. High-risk consumption was reduced by $29 \%$ in G3 compared to G1 and by $26 \%$ compared to G2. For every 100 people to whom the brief intervention was applied, there was a reduction of 24 cases (26 in relation to G1 and 23 in relation to G2), indicating that out of every four students to whom 
the intervention was provided, one benefited. Similar results were found for the variable high-risk consumption. In terms of alcohol-related problems, there was a $17 \%$ reduction of positive cases in G3 compared to G1, and a $7 \%$ reduction compared to G2. For every 100 students who received a brief intervention, there was an average reduction of nine cases, and one student benefited out of every 13 who received the BI.

Table 1. Descriptive measures of the quantity of alcohol consumption, related problems, and risky consumption in Phases 1 and 2 of the randomized clinical trial with secondary school students in Mar del Plata, 2011

\begin{tabular}{|c|c|c|c|c|c|c|c|c|c|c|c|c|}
\hline & \multicolumn{4}{|c|}{ G1 } & \multicolumn{3}{|c|}{ G2 } & \multicolumn{5}{|c|}{ G3 } \\
\hline & $\%$ & $\mathrm{M}(\mathrm{SD})$ & CI $95 \%$ & $\mathrm{R}$ & $\%$ & $\mathrm{M}(\mathrm{SD})$ & CI $95 \%$ & $\mathrm{R}$ & $\%$ & $\mathrm{M}(\mathrm{SD})$ & CI $95 \%$ & $\mathrm{R}$ \\
\hline \multicolumn{13}{|l|}{ Phase 1} \\
\hline Consumption & & $2.38(3.63)$ & $1.59-3.36$ & $0-16$ & & $2.23(3.32)$ & $1.94-4.62$ & $0-17$ & & $2.46(3.63)$ & $1.7-5.25$ & $0-20$ \\
\hline $\begin{array}{l}\text { High-risk } \\
\text { consumption }\end{array}$ & 41 & & $29-53$ & & 37 & & $25-52$ & & 43 & & $27-59$ & \\
\hline $\begin{array}{l}\text { Alcohol-related } \\
\text { problems }\end{array}$ & & $5.28(6.16)$ & $3.88-7.03$ & $0-22$ & & $4.67(5.4)$ & $3.29-6.21$ & $0-20$ & & $4.75(6.06)$ & $3.05-6.77$ & $0-25$ \\
\hline \multicolumn{13}{|l|}{ Phase 2} \\
\hline Consumption & & $2.69(3.75)$ & $1.90-3.76$ & $0-21$ & & $2.45(3.35)$ & $1.86-4.77$ & $0-18$ & & $2.55(6.06)$ & $1.23-9.96$ & $0-40$ \\
\hline $\begin{array}{l}\text { High risk } \\
\text { consumption }\end{array}$ & 41 & & $29-53$ & & 40 & & $27-54$ & & 23 & & $11-36$ & \\
\hline $\begin{array}{l}\text { Alcohol-related } \\
\text { problems }\end{array}$ & & $4.57(5.15)$ & $3.38-5.96$ & $0-19$ & & $4(4.56)$ & $2.87-5.31$ & $0-16$ & & $3.45(4.95)$ & $2.09-5.09$ & $0-21$ \\
\hline
\end{tabular}

Notes. cI: Confidence Interval. R: Range G1: Screening, G2: Screening and evaluation, G3: Screening, evaluation, and intervention 

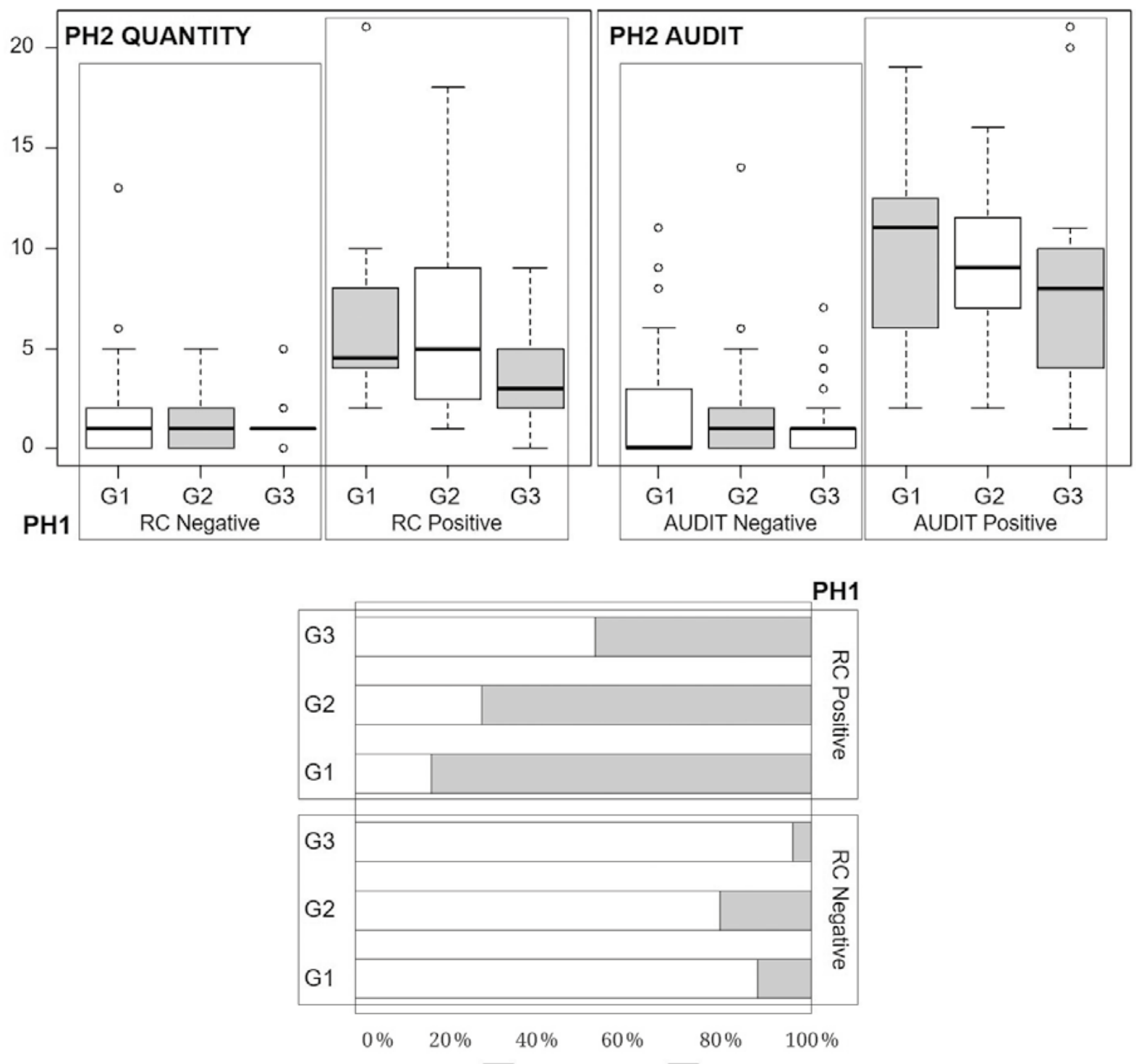

PH2 RC $\square$ Positive $\square$ Negative

Figure 2. Differences in the quantity of alcohol consumption, related problems, and risky consumption in Phases 1 and 2 of the randomized clinical trial among secondary school students, Mar del Plata, 2011

Notes: PH: Phase, G1: Screening, G2: Screening and evaluation, G3: Screening, evaluation, and intervention, RC = Risky Consumption, AUDIT = Alcohol Use Disorders Identification Test. 
Table 2. Differences in the quantity of alcohol consumed and related problems in G1, G2, and G3 of secondary school students, according to AUDIT 2011

\begin{tabular}{llll}
\hline Variable & $\boldsymbol{\beta}$ & CI 95 \% & $\mathbf{p}$ \\
\hline Quantity of alcohol consumed, Phase 2 & & & \\
\hline Quantity (Phase 1) & 1.40 & $1.17-1.63$ & .0001 \\
\hline G3 vs. G1 & 2.13 & $.07-2.87$ & .0019 \\
\hline G3 vs G2 & 1.47 & $.79-3.47$ & .0392 \\
\hline$R^{2}$ & .61 & & \\
\hline$F$ & 45.06 & & \\
\hline Problems due to consumption of alcohol, Phase 2 & & & \\
\hline Related problems (Phase 1) & .67 & $.53-.83$ & .0001 \\
\hline G3 vs G1 & .71 & $-.67-2.55$ & .3620 \\
\hline G3 vs G2 & .93 & $-.23-2.25$ & .2530 \\
\hline$R^{2}$ & .64 & & \\
\hline$F$ & $50.5^{* *}$ & & \\
\hline
\end{tabular}

Notes: AUDIT: Alcohol Use Disorders Identification Test. G1: Screening, G2: Screening and evaluation, G3: Screening, evaluation, and intervention.

Table 3. Effectiveness for reduction (or maintenance of low risk) of alcohol consumption, risky consumption, and related problems based on experimental conditions and risk groups among secondary school students, 2011

\begin{tabular}{|c|c|c|c|c|c|c|c|c|}
\hline \multirow[b]{3}{*}{ Variables } & \multicolumn{4}{|c|}{$\begin{array}{l}\text { Reduction or maintenance } \\
\text { of low risk }\end{array}$} & \multicolumn{4}{|c|}{ Clinical significance $\dagger$} \\
\hline & \multicolumn{2}{|c|}{ No Risk } & \multicolumn{2}{|c|}{ Risk } & \multirow[b]{2}{*}{$\mathrm{RR}$} & \multirow[b]{2}{*}{ RRR } & \multirow[b]{2}{*}{ ARR } & \multirow[b]{2}{*}{ NNT } \\
\hline & $\%$ & CI $95 \%$ & $\%$ & CI 95\% & & & & \\
\hline \multicolumn{9}{|l|}{ Quantity } \\
\hline G1 & 36 & $23-50$ & 64 & $36-86$ & .71 & 28.57 & 25.7 & .04 \\
\hline G2 & 39 & $22-56$ & 67 & $42-92$ & .74 & 25.93 & 23.3 & .04 \\
\hline G3 & 27 & $12-42$ & 90 & $70-100$ & --- & --- & --- & --- \\
\hline \multicolumn{9}{|c|}{ Risky consumption } \\
\hline G1 & --- & --- & 59 & $45-71$ & .73 & 26.78 & 20.7 & .05 \\
\hline G2 & --- & --- & 60 & $46-75$ & .78 & 21.86 & 16.9 & .06 \\
\hline G3 & --- & --- & 77 & $66-89$ & --- & --- & --- & --- \\
\hline \multicolumn{9}{|c|}{ Related problems } \\
\hline G1 & 55 & $39-71$ & 65 & $40-85$ & .83 & 17.30 & 13.6 & .07 \\
\hline G2 & 45 & $30-64$ & 73 & $48-93$ & .93 & 6.7 & 5.3 & .19 \\
\hline G3 & 57 & $40-73$ & 79 & $57-100$ & --- & --- & --- & --- \\
\hline
\end{tabular}

Notes. G1: Screening, G2: Screening and evaluation, G3: Screening, evaluation, and intervention. RR: Risk reduction, RRR: Relative Risk Reduction, ARR: Absolute Risk Reduction, NNT: Number need to treat to reduce an event.

† Analyses demonstrate the reduction of all variables for risk groups in G3 compared to G1 and G2. 


\section{Discussion}

$\mathrm{I}^{\mathrm{n}}$ $n$ this work we have evaluated the effectiveness of a program for BI with adolescents in a school environment to reduce the consumption of alcohol and related problems. While the descriptive analyses do not indicate differences in the average quantity of alcohol consumed, the charts and regression analyses indicate a reduced quantity of alcohol consumption in the group to which BIs were provided. One possible explanation for this is the sensitivity of the mean to extreme values. Extreme values were present in all groups.

There were not significantly fewer alcohol related problems in any group, despite the fact that a greater reduction in these problems was observed in G3 with respect to the average, and in particular in the positive for alcohol-related problems according to AUDIT. While there is evidence that assessing consumption leads to decreased drinking, probably because it increases subjects' cognitive awareness over their consumption, these changes may be more long lasting and related problems often decrease more significantly among those who have had a BI $(8,10,25)$. In line with the literature, the reduction of problems seemed to be less notable in the screeningonly group compared to those who received more extensive evaluation (10). The other most important hypotheses about the reduction observed in control groups entailed contamination among conditions and regression to the mean (10). These were not examined in this study, but could be the subject of future research endeavors. High risk consumption decreased in all the groups, but results indicate that it was significantly reduced in the вi group ( $24 \%$ and $23 \%$ less than in G1 and G2, respectively). A metanalysis concludes that BI would not be more effective in high-risk groups among university students, although it is so among adolescents (7). High-risk adolescent participants experienced a greater benefit from BIS, probably because BIs would not be as effective in groups at risk or not at risk (as opposed to high-risk) who make up the majority of secondary school students.

Despite the lack of statistical significance, the analyses of clinical significance indicate a clear reduction within the group that received BIs in comparison with the other groups, it is possible that the non-significance would be due, in part, to the size of the sample, which may have been insufficiently large to evaluate differences. It is estimated that in order to find differences, there should be at least 120 students in each group, pointing to a limitation of this study. As for the evaluation of clinical significance, these results indicate meaningful reductions in high-risk consumption, and support the effectiveness of the brief intervention. Brief Intervention, which can be carried out in about 10-15 minutes and administered by school personnel after a short training session, constitute a valuable tool for reducing alcohol consumption among adolescents (8). For every seven students who receive the brief intervention, alcohol consumption and related problems can be reduced for one of them.

Although the results of this study cannot be generalized to other populations (for instance, non-schooled adolescents), it provides information relevant to the effectiveness of вI. The 
importance of continuing research in this area is recognized, and the population of subjects should be broadened to include adolescents who did not attend school or who attend public schools. The effectiveness of each element of вг should be studied independently, as should the intervention's long-term effects. In addition to expanding research to new environments, and generally increasing the body of evidence regarding the effectiveness of BI, other avenues of research that were not included in this study should he explored. These should include identifying the subjects who best respond to BI, and the most important factors in bringing about behavioral change among different populations. In addition, research should be conducted on how to ensure that those who are referred to treatment complete that treatment, and on identifying the barriers to implementing вв in different contexts and scenarios (26).

\section{Acknowledgements}

This study was carried out with partial funding from the Universidad Nacional de Mar del Plata and the Consejo Nacional de Investigaciones Científicas and Técnicas of Argentina.

\section{Conflicts of interest}

There are no conflicts of interest to declare.

\section{References}

1. World Health Organization. Global strategy to reduce the harmful use of alcohol. Geneva: World Health Organization; 2010.

2. World Health Organization. Global status report on alcohol and health-2014. Geneva: World Health Organization; 2014.

3. Secretaría de Programación para la Prevención de la Drogadicción y la Lucha contra el Narcotráfico. Sexta Encuesta Nacional sobre Consumo de Sustancias Psicoactivas en Estudiantes de Enseñanza Media [internet]. [cited 2016 ago 8] Available in: http://scripts. minplan.gob.ar/octopus/archivos.php?file $=4121$

4. National Institute of Alcohol Abuse and Alcoholism. NIAAA Council approves definition of binge drinking. NIAAA newsletter. 2004;3:3.

5. Conde K, Brandariz RA, Cremonte M. Problemas por uso de alcohol en estudiantes secundarios y universitarios. Rev. Chil. Neuro-Psiquiat. 2016;54(2):84-93.

6. White A, Hingson R. The burden of alcohol use: excessive alcohol consumption and related consequences among college students. Alcohol Res. 2013;35(2):201-18. 
7. Tanner-Smith EE, Lipsey MW. Brief alcohol interventions for adolescents and young adults: A systematic review and meta-analysis. J Subst Abuse Treat. 2015;51:1-18.

8. Nilsen P, Kaner E, Babor T. Brief intervention, three decades on. Nord Stud Alcohol DR. 2008;25:453-67.

9. Miller WR, Rollnick S. La entrevista motivacional. Ciudad: Paidós; 1999.

10. Cremonte M, Monteiro M, Chepitel C. Interventions to reduce alcohol-related injury in the emergency department: Screening, brief intervention and monitoring. En: Monteiro M, Cherpitel C, editors. Prevention of Alcohol-Related Injuries in the Americas: From Evidence to Policy Action. Washington D.C.: PAHO; 2013. p. 159-68.

11. Babor TF, McRee BG, Kassebaum PA, Grimaldi PL, Ahmed K, Bray J. Screening, Brief Intervention, and Referral to Treatment (SBIRT) toward a public health approach to the management of substance abuse. Subst Abus. 2007;28(3):7-30.

12. US Department of Health and Human Services. Helping patients who drink too much: a clinician's guide. National Institutes of Health. National Institute on Alcohol Abuse and Alcoholism. Ciudad: NiH Publication; 2005.

13. Bernstein E, Bernstein J, Levenson S. Project ASSERT: an ED-based intervention to increase access to primary care, preventive services, and the substance abuse treatment system. Ann Emerg Med. 1997;30(2):181-9.

14. Beaton A, Shubkin CD, Chapman S. Addressing substance misuse in adolescents: a review of the literature on the screening, brief intervention, and referral to treatment model. Curr Opin Pediatr. 2016;28(2):258-65.

15. Magill M, Colby SM, Orchowski L, Murphy JG, Hoadley A, Brazil LA, et al. How does brief motivational intervention change heavy drinking and harm among underage young adult drinkers? J Consult Clin Psychol. 2017;85(5):447.

16. Schermer CR. Feasibility of alcohol screening and brief intervention. J. Trauma Acute Care Surg. 2005;59(3):S119-23.

17. Sise MJ, Sise CB, Kelley DM, Simmons CW, Kelso DJ. Implementing screening, brief intervention, and referral for alcohol and drug use: the trauma service perspective. J. Trauma Acute Care Surg. 2005;59(3):S112-8.

18. Monteiro MG. Alcohol y salud pública en las Américas: Un caso para la acción. Ciudad: Pan American Health Organization; 2007.

19. Nilsen P, Baird J, Mello MJ, Nirenberg T, Woolard R, Bendtsen P, et al. A systematic review of emergency care brief alcohol interventions for injury patients. J Subst Abuse Treat. 2008;35(2):184-201.

20. Saunders JB, Aasland OG, Babor TF, Fuente de la JR, Grant M. Development of the alcohol use disorders identification test (AUDIT): wHo collaborative project on early detection of persons with harmful alcohol consumption-II. Addiction. 1993;88(6):791-804.

21. White HR, Labouvie EW. Towards the assessment of adolescent problem drinking. J. Stud. Alcohol. 1989;50(1):30-7.

22. Cremonte M, Brandariz RA, Biscarra A, Lichtenberger A, Marconato M. Análisis dimensional de la versión argentina del Rutgers Alcohol Problem Index (RAPI). Presentado en: VI Congreso Atlántico de Psiquiatría. 2010; Buenos Aires 
23. Cremonte M, Ledesma RD, Cherpitel CJ, Borges G. Psychometric properties of alcohol screening tests in the emergency department in Argentina, Mexico and the United States. Addict Behav. 2010;35(9):818-25.

24. Knight JR, Sherritt L, Harris SK, Gates EC, Chang G. Validity of brief alcohol screening tests among adolescents: a comparison of the AUDIT, POSIT, CAGE, and CRAFFT. Alcohol. Clin. Exp. Res. 2003;27(1):67-73.

25. Baer JS, Kivlahan DR, Blume AW, McKnight P, Marlatt GA. Brief intervention for heavy-drinking college students: 4-year follow-up and natural history. Am. J. Public Health. 2001;91(8):1310-6.

26. D’Souza-Li L, Harris SK. The future of screening, brief intervention and referral to treatment in adolescent primary care: research directions and dissemination challenges. Curr Opin Pediatr. 2016;28(4): 434-40. 